УДК $316.4,330$

DOI: 10.18101/1994-0866-2019-4-32-42

\title{
НАКАНУНЕ ГЕГЕМОНА? МИР-СИСТЕМНЫЙ ПОДХОД К ПЕРСПЕКТИВЕ ГЛОБАЛЬНОГО ЛИДЕРСТВА КНР
}

\author{
(C) Купряшкин Илья Владимирович \\ кандидат философских наук, доцент, \\ Дальневосточный федеральный университет \\ Россия, 690091, г. Владивосток, ул. Суханова, 8 \\ E-mail: kupryashkin.iv@dvfu.ru
}

Текст посвящен памяти основателя мир-системного анализа, классика исторической социологии, президента (1994-1998) международной социологической ассоциации Иммануила Валлерстайна. Автор статьи присоединяется к дискуссии относительно перспектив глобального лидерства Китайской Народной Республики в современной мир-экономике. Он задается вопросом: «Являемся ли мы свидетелями становления гегемонии КНР, в то время как США утрачивают лидерские позиции?» Представлены достижения Китая и возможности влиять на мировую экономику в самых разных аспектах. Кратко рассмотрены внутренние противоречия и проблемы развития КНР. Сделан обзор с акцентом на мир-системный подход, разрабатываемый Валлерстайном, некоторых идей и сюжетов относительно перспектив гегемонии Китая. В заключении автор не дает однозначного ответа на свой вопрос и предлагает новые сюжеты для аналитики.

Ключевые слова: общество; Китай; США; гегемония; мир-системный анализ; глобализация; Иммануил Валлерстайн, лидерство.

\section{Для цитирования}

Купряшкин И. В. Накануне гегемона? Мир-системный подход к перспективе глобального лидерства КНР // Вестник Бурятского государственного университета. Философия. 2019. Вып. 4. С. 32-42.

\section{Введение}

Перспективы гегемонии КНР в ситуации утраты влияния США - тема сегодня крайне актуальная и содержит пока больше вопросов, чем ответов. С учетом сказанного выше и сложности проблемы я не надеюсь в этом тексте дать исчерпывающие ответы. Удовлетворительным результатом будет хотя бы постановка частных вопросов внутри большого, скрытого в названии. Думается, этому будет способствовать беглый обзор некоторых сюжетов в современных дискуссиях. Особое внимание попробую уделить мир-системной парадигме, с позиций которой считаю наиболее уместным рассматривать современные глобальные процессы. Отмечу любопытный факт - китайский язык стал единственным, на который переведены все 500 комментариев И. Валлерстайна о различных мировых событиях, последний из которых увидел свет 1 июля 2019 г. [55]. 31 августа 2019 г. весь мир оплакивал мэтра современной социальной науки. Пожалуй, лучшее, что мы, как последователи, можем сделать - это продолжать исследования в рамках подхода, навсегда связанного с именем профессора Иммануила Валлерстайна [13]. Я буду 
И. В. Купряшкин. Накануне гегемона? Мир-системный подход к перспективе глобального лидерства KHP

рассматривать достижения КНР и Пекинский консенсус, проблемы и противоречия в развитии Китая, исследовательские оценки возможностей глобальной гегемонии КНР.

\section{Достижения КНР и Пекинский консенсус}

Известный российский китаевед В. Портяков считает, что к декларации ученых из КНР о достижении Китаем паритета с США по комплексной мощи стоит отнестись вполне серьезно [11, с. 439-448]. ВВП КНР в 2016 г. в 4,22 раза превысил ВВП 2000 г. Таким образом, намечавшееся на 2020 г. увеличение ВВП страны в 4 раза по сравнению с началом столетия достигнуто на четыре года раньше срока [12, с. 102]. Другая иллюстрация роста ВВП КНР: в 1978 г. ВВП на душу населения составлял менее 100 долл. США, а в 2015 г. ВВП Китая на душу населения приблизился к 8000 долл. [43]. Рост Китая влечет изменения во многих сферах мировой экономики. Например, прослеживается влияние Китая даже в сфере международного экономического права [24]. Данные убедительно свидетельствуют о том, что вход Китая в мировой рынок чеснока имел пагубные последствия для производства и экспорта этого продукта в Мексике [37]. Сегодня Китай занимает первое место в мире по потреблению люксовых изделий [3]. Т. Дейч отмечает, что на XIX съезде Коммунистической партии Китая руководство во главе с Си Цзиньпином консолидировало власть и повысило влияние Китая на мировой арене. За основу во внешней политике взята концепция «единой судьбы человечества». Пекин и дальше будет исходить из принципа невмешательства в дела других и выступать за мирное решение конфликтов. Китай намерен укреплять свои международные позиции и защищать свои интересы, значит, усилит внимание, в том числе, к Африке [4]. Роль Китая в обеспечении безопасности в Африке действительно растет, как и бизнес-интересы на континенте. Во всех отношениях Китая с ключевыми региональными организациями на континенте имеются аспекты мира и соображения безопасности [18]. В. И. Бартенев призывает освободиться от иллюзий о «нетрадиционных» донорах, имея в виду Китай, поскольку тот не отчитывается ОЭСР и не выставляет реципиентам политических требований [2]. В. Н. Коваленко предполагает, что Африка становится полигоном, где на практике реализуется попытка тиражирования китайской социально-экономической модели в иных цивилизационных условиях, что чрезвычайно важно для Китая в качестве претендента на роль великой державы [7, с. 33-34]. Пекин активно предлагает миру новые, синоцентричные инициативы. Одной из наиболее известных является «Один пояс - один путь». Цель - занять одну из ключевых ролей в глобальном экономическом управлении и постепенное выстраивание китаецентричной системы международных правил, норм и институтов [8]. Глобальный проект содействия экономическому развитию и обменов между Китаем и более чем 60 странами набирает ход. В рамках проекта Китай может создать новую систему безопасности как на морском, так и на сухопутном маршрутах. Решение может быть в международных компаниях, которые обеспечивают вооруженную частную безопасность, специальную оценку рисков, страхование и смягчение последствий кризиса [20]. Ряд экспертов справедливо полагает, что «Один пояс - один путь» является не только региональным проектом, но отражает великую глобальную стратегию достижения «китайской мечты» [45]. Осмысление проекта «Один пояс - один путь» ведется сегодня многими мировыми интеллектуальными центрами, и этот процесс весьма далек от завершения [23]. У экспертов есть опасения, что Центральная Азия может 
стать более зависимой от экономики и политики Китая. Традиционно Москва считает этот регион частью российской исторической сферы влияния. Могут ли разворачивающиеся процессы привести к усилению напряженности в отношениях между Россией и Китаем за влияние в Центральной Азии в будущем остается вопросом для исследователей [29]. Поскольку объем китайских инвестиций в России составляет $1 \%$ от общих объемов инвестиций Китая за рубежом, карта Москвы в диалоге с Пекином вряд ли может быть экономической, при очевидной силе геополитических инструментов [17, с. 209-220]. С точки зрения Соединенных Штатов, китайские глобальные инициативы бросают вызов их доминирующей роли в существующей международной системе. С одной стороны, так как международные структуры меняются, Китай будет иметь возможность реализовать свою собственную повестку в области развития через «Один пояс - один путь», но с другой стороны, бифуркация может обнажить и неожиданные для КНР препятствия [52]. Авторы доклада Конгрессу США, предполагают, что Китай, скорее всего, будет стремиться создавать дополнительные объекты военной логистики в страны, с которыми он имеет давние, дружеские отношения. Соединенные Штаты должны продолжить искать направления сотрудничества с конкурентами, сохраняя способность успешно соперничать с позиции силы. США необходимо стремиться к конструктивным и ориентированным на результат отношениям с Китаем [19]. Новые стратегические амбиции Китая в мире волнуют Индию как еще одну бурно развивающуюся экономику. Взаимодействие Китая с региональными элитами строится на убеждении азиатских стран в преимуществах привязки их программ развития к китайской экономической политике, и в то же время заверениях партнеров в доброкачественном характере подъема КНР. Это значимо для исследований вообще и с точки зрения перспективы развития Индии, в частности [42].

\section{Проблемы и противоречия в развитии КНР}

Предоставим голос скептикам относительно возможной гегемонии Китая. По их мнению, экономика страны изобилует противоречиями и зависит от США. Более того, внутренние проблемы, включая угрозу терроризма, беспорядки угнетенных религиозных меньшинств, растущую безработицу, нехватку воды и кризис со здоровьем, ограничивают способность Китая заботиться о внешнем мире. Экономические, социальные и экологические проблемы КНР, требующие много внимания, предотвратят появление мирового лидерства [33]. Экологические ограничения называются едва ли не главным вызовом для развития Китая [51]. При сохранении сегодняшних тенденций Китай будет испытывать ежегодно рост городского населения, который превышает общее население большинства народов мира в 2000 г. Такого роста (городского) населения в пределах одной страны ранее не было в истории человечества. Вероятно, приблизиться к подобному может только Индия. Это означает, что нагрузка на имеющиеся ресурсы, такие как земля, вода и энергия намного выше, чем на сопоставимых этапах Европейского опыта урбанизации. Таким образом, это рост городского населения создает огромные проблемы для устойчивых моделей урбанизации [38]. Глобализация оказывает глубокое влияние на все аспекты городской жизни и в КНР это вызов заметен как нигде [28]. Ученые даже утверждают, что судьба урбанизации Китая вполне может повлиять и на глобальную урбанизацию [26]. Поражая масштабами спортивных стадионов и торговых центров, сотни новых городов в Китае стоят пустыми, а к 2030 г. планируется построить еще сотни. Между тем городское население страны 
И. В. Купряшкин. Накануне гегемона? Мир-системный подход к перспективе глобального лидерства KHP

составило уже больше миллиарда. Города-призраки Китая - это все еще вызов для правительства [47]. Ближайшее будущее в области прав человека в КНР кажется мрачным. Китайское правительство контролирует один из самых строгих онлайн-цензурных режимов в мире. Школы и государственные СМИ непрестанно рекламируют верховенство Коммунистической партии Китая и Си Цзиньпина как лидера. Проблемы в Синьцзяне, номинально автономной области с 11 миллионами тюркоязычных мусульманских уйгуров, не решены и периодически усугубляются. Сложности в отношениях с Гонконгом известны во всем мире. Безусловно, возросшее глобальное влияние Китая означает, что многие из проблем с правами человека в настоящее время имеют международные последствия [36]. Отметим, что впечатление о стране, которая управляется жестким контролем, не совсем точно соответствует реальности. По мнению некоторых исследователей, современный Китай чрезмерно контролируется, но неадекватно управляется [30]. Проблемы с авторским правом в современном Китае можно отнести к этой же группе проблем [50]. Китай с его быстрорастущей экономикой, крупнейшим населением и развитыми диаспорами все больше интегрируется в мировую систему. Поскольку китайский народ вновь соединился со своими зарубежными диаспорами, китайская эмиграция может определить новый «китайский век». Потенциал эмиграции из Китая уже сравнивается с «Цунами на горизонте» [40]. Не менее важной задачей, поставленной руководством КНР, являются повышение культурной привлекательности и рост мягкой силы. На этом пути есть определенные успехи, но до заветной цели еще далеко. Согласно Индексу мягкой силы 2018 г., Китай занимает 27-е место в мире [49]. Обычные люди в большинстве европейских стран, как показали опросы, считали, что Китай и Европа не имеют общих ценностей и интересов, стороны не смогут сотрудничать по международным вопросам. Респонденты высказывались о значимости различий китайцев и европейцев, осложняющих сотрудничество [34]. В этом месте интересен случай, рассказанный М. Санделом [39, р. 278]. Его друг и бывший коллега из Гарварда Ту Вейминг однажды отметил, что Китай является цивилизацией учебы, тогда как Запад является цивилизацией преподавания. Он не расценивал это как комплимент Западу. Речь шла о том, что общества, которые считают себя моделью для всего остального мира, впадают в определенную гордость. Их инструкции переходят в проповеди. Помимо порождения негодования цивилизация, стремящаяся к преподаванию и проповеди, теряет свою способность встречать мир, слушать и учиться. Суй Ян, задавая европейцам вопрос «Что вы знаете о Китае?», получал в большинстве случаев ограниченные ответы, вроде, «Великая китайская стена», «Шелк», «Председатель Мао» и т. д. Большое количество людей отвечали ему: «почти ничего» [48]. Китай уже добился значительного прогресса в развитии новых высокотехнологичных отраслей, но до полной реорганизации промышленности еще далеко и на этом пути тоже есть затруднения [25]. Этой цели служит, например, сотрудничество КНР и Германии по проектам «Сделано в Китае - 2025» и Industrie 4.0 соответственно. Сотрудничество открывает дополнительные возможности как для реорганизации китайской промышленности, так и для развития потенциала немецких компаний $[15$, с. $338-351]$.

При всем бурном росте китайской экономики она не является единым монолитом, рыночная интеграция Китая была неравномерной. Экономический рост привел к увеличению неравенства доходов между прибрежными регионами Китая и 
его центральным и западным районами [44]. О степени устойчивости КНР как глобализационного ядра тоже есть сомнения у экспертов. Китай как экономический актор и как социум не застрахован от внутренне мотивированных затруднений, снижения темпов роста, вплоть до глубокого системного кризиса и социально-политического коллапса. Китайская экономика - одна из наиболее сложно управляемых [16, с. 68]. Как видно, оборотной стороной достоинств и преимуществ современного Китая являются внутренние противоречия развития страны. Приведенный выше обзор поможет уточнить координаты Китая в современной мир-системе, опираясь на работы сторонников мир-системной парадигмы в последующей части текста. Прежде чем переходить к сторонникам мир-системного подхода, зафиксируем в качестве рамки ситуацию в ее основных характеристиках. Эксперты сегодня говорят о кризисе существующего миропорядка в разных сферах [9]. Суммируя, исследователи отмечают, что к многополярному миру ведут: 1) рост значимости незападных стран в экономике мира; 2) международные миграции и конфликт элит Запада; 3) рост правых настроений на Западе; 4) проблемы США в отношениях с Китаем, Европой и Россией; 5) спорные эффекты от принятых решений в технологической, социальной и политической сфере [10]. По мнению экспертов ИМЭМО РАН [14, с. 63-64], можно говорить о трех возможных сценариях развития международных отношений. Простейший вариант, на который надеется Китай, заключается в том, что США уступят лидерство мирно и согласятся с тем, что растущий Китай будет постепенно занимать их место. Если реализуется обратный сценарий, то США пойдут на силовой конфликт с целью не допустить китайского лидерства. Третий обсуждаемый сценарий - это раздел сфер влияния, напоминающий старый биполярный мир, разделяющий мир на два лагеря - либеральный капитализм и авторитарный капитализм.

\section{Мир-системный взгляд на Китай}

При взгляде на возможности китайской гегемонии нам следует обратиться к ряду классических версий мир-системного подхода. Начать стоит с самого И. Валлерстайна. Классик уделял немало внимания процессу, который принято называть возвышением Восточной Азии. В 1997 г. И. Валлерстайн выступал на симпозиуме «Перспективы капиталистической мир-системы в начале XXI века», организованном Институтом международных исследований Университета Мейдзи Гакин в рамках программы «Перспективы международных исследований» в Токио. Наиболее вероятным следующим гегемоном он назвал Японию, которая сможет одержать победу как морская держава, опирающаяся на помощь и поддержку предыдущего гегемона - своего союзника Соединенных Штатов Америки [54]. В своем последнем комментарии на тему возможного лидерства КНР профессор Валлерстайн писал: «В любом случае скрытый танец между Китаем и Соединенными Штатами, этот поиск партнерства будет оставаться основной геополитической реальностью в мир-системе на ближайшие десятилетия. Китай и США станут партнерами» [53]. Напомню, что согласно мэтру мир-система переживает кризис и предсказать его исход невозможно. Еще один классик мир-системного подхода Андре Гундер Франк, как известно, считал, что современной системе 5000 лет и ее центром традиционно был Китай. Некоторое время назад центр капитализма сместился на Запад и сегодня все возвращается на круги своя. Центр мировой экономики снова возвращается в Китай [27]. Рассказ о классиках мир-системного анализа был бы не полным без упоминания Джованни Арриги. Его последняя книга 
И. В. Купряшкин. Накануне гегемона? Мир-системный подход к перспективе глобального лидерства KHP

называлась «Адам Смит в Пекине: что получил в наследство XXI век». Название книги самым красноречивым образом говорит о ее содержании и прогнозе автора [21]. На мой взгляд, нужно обозначить еще несколько принципиально важных сюжетов для любого исследователя мир-системы. Исследователям мир-системы известно, что переходы гегемонии не были краткосрочными. Процесс перехода всегда сопровождался вооруженными конфликтами за новую конфигурацию мира. Как известно, таких лидеров в истории мир-системы, по наиболее часто упоминающейся версии, последовательно было три: Нидерланды, Великобритания и США. Этот сюжет означает, что даже если мы вступили сегодня в переходную эпоху, скорее всего, переход будет долгим. Реальный системный переход продолжался целый век (с 1900 по 2000 г.) и только недавно был завершен. Столетие перехода было кровавым, репрессивным (для всех сторон) и беспорядочным. Сейчас все закончилось, и следующий системный переход, вероятно, не будет короче. Исследователи международных отношений все еще живут в старой системе и многие из них, похоже, жаждут старых войн. Между тем новая система будет иметь свои собственные характеристики [22, р. 69]. Другой сюжет касается армии. Несомненно, гегемон это тот, кто может защищать сложившееся мироустройство. Противоречие состоит именно в том, что чем больше гегемон тратит усилий на поддержание гегемонии, на военную сферу, тем яснее это означает его ближайший кризис и упадок. Последний сюжет, который обязательно нужно здесь отметить, касается монополий. Гегемон - это тот, кому удается создать монополию на рынках производства, обмена и потребления. Лидер должен предложить нечто новое и зафиксироваться благодаря этим новациям в статусе лидера. Поскольку монополии не вечны, со временем преимущество теряется, а возможность оставаться лидером напрямую связана с возможностью постоянно предлагать новации и формировать новые монополии. Этот сюжет связан с предыдущим, поскольку чем больше слабеющий гегемон тратит на вооружение, тем меньше возможности остается на развитие экономики. Пол Кеннеди отмечает, что сегодня и Китай и Германия изо всех сил стремятся избежать чрезмерных военных расходов, ибо это может негативно сказаться на их темпах роста экономики в долгосрочной перспективе. Включаясь в войну или принимая решение о перенаправлении значительной части своих «производительных сил» на создание «непродуктивного» военного вооружения, государство рискует разрушить свою национальную экономическую базу, особенно если оно нацелено на долгосрочное инвестирование доходов в рост экономики [6, с. 786]. Действительно, ситуация, при которой страна, равная 20\% населения мира, переходит из состояния периферии в полупериферию за короткий период времени, беспрецедентна. Такая новая форма многослойной мировой экономики создаст усиливающееся давление на страны ядра мир-системы [31]. Сегодня Китай, как полагают многие, способен возглавить усилия, направленные на свержение мирового господства США. Возможных сценариев будущего мировой системы два: полупериферийное трансформационное поглощение системы или продолжение гегемонии США во втором раунде [35]. По-видимому, задача, стоящая перед следующим гегемоном глобальной системы, состоит также в том, чтобы учитывать деградацию, которую производственное накопление наносит природной среде и людям, обеспечить устойчивое воспроизводство природы и труда [32]. Будет ли эта задача посильна для КНР? Структурные условия, похоже, подталки- 
вают Китай к сохранению глобального статус-кво в очень последовательной манере. Изменение геополитической конфигурации межгосударственной системы является важной частью мировых процессов построения гегемонии. Когда меняется территориальная конфигурация межгосударственной системы, как в случае с Южным Суданом и Крымом, Китай старается избегать конфликтов с великими державами. С этой точки зрения, даже если Китай станет новым гегемоном, то межгосударственная система, которой он будет руководить, не будет новой (то есть более «прогрессивной» и «более демократичной») системой [46]. Дискурс о властных основаниях миропорядка еще более усложняет прогнозирование. Конец глобализации по-американски обнажает скорее смутные перспективы. Ситуация, когда миром, кажется, уже никто не правит, становится опасной для всех [5, с. $3-$ 18]. Упадок власти означает, по мысли Мозеса Наима, что пророчить гегемона или клуб элитных стран сегодня бессмысленное занятие [41]. Стало быть, претенденты на гегемонию вынуждены будут отвечать еще на ряд сложных вопросов. Лидерство, каково оно - политическое или военное? Ведомые - подданные или союзники? Каковы узы между ними - добровольные или вынужденные? Каждая следующая форма, в которой являлась гегемония, содержала в себе эту двусмысленность [1, с. 275]. Ослабление нынешнего гегемона еще не означает вероятного нового претендента на мировую гегемонию. До сих пор Китаю удалось расширить свои сети в регионах, которые являются маргинальными в мировом порядке под руководством США. Приведет ли нынешняя стратегия Китая к мировой гегемонии, остается неясно [56].

\section{Заключение}

В заключение сформулирую для себя несколько задач или вопросов. Мы наблюдаем конец капитализма или все-таки завершение американского системного цикла накопления/упадка гегемонии? В ситуации конца географии возможна симуляция распада мир-системы на ряд мир-империй и мини-систем с их борьбой, чтобы обеспечить в последующем новую экспансию системы (например, в Африке) или «буфер поддержки» (ситуация, напоминающая биполярный мир прошлого века)? Есть ли шансы у США вернуть лидерскую позицию, и теряют ли они ее на самом деле (может из-за экономических успехов на Востоке просто показалось, что США в упадке)? Хватит ли у США воли и возможностей зайти на новый круг (т.е. выскочить с гонки вооружений или использовать новые войны в свою пользу)? Насколько эффективны наши теории для глобальных прогнозов, если гегемония после США прочится всякий раз новому государству в период его подъема? Кажется, мы пока еще не очень хорошо умеем прогнозировать глобальные исторические тренды или события. Хорошо бы нам разобраться с этим, не дожидаясь новых плачевных уроков истории.

Исследование проведено при финансовой поддержке РФФИ, грант № 17-2710001. The article is down with support of the Russian Foundation for Basic Research. Grant № 17-27-10001.

\section{Литература}

1. Андерсон П. Перипетии гегемонии / пер. с англ. Д. Кралечкина; под науч. ред. В. Софронова. М.: Изд-во Ин-та Гайдара, 2018. 296 с. 
И. В. Купряшкин. Накануне гегемона? Мир-системный подход к перспективе глобального лидерства KHP

2. Бартенев В. И. Внешняя помощь и качество государственного управления: освобождение от иллюзий // Полис. Политические исследования. 2018. № 6. С. 67-79. DOI: $10.17976 /$ jpps/2018.06.05

3. Горбачёва С. Ю. «Новые китайцы» в новом Китае. Перемены в морали и нравственности в поднебесной в XXI веке // Азия и Африка сегодня. 2016. № 9. С. 64-67.

4. Дейч Т. ХІХ Съезд КПК: значение для Китая и его внешней политики // Азия и Африка сегодня. 2018. № 5. С. 11-18.

5. Дерлугьян Г. Кто-нибудь вообе правит нашим миром? // Закат империи США: Кризисы и конфликты / пред. Б. Кагарлицкого; И. Валлерстайн, С. Амин, С. Джордж и др.; Институт глобализации и социальных движений. М.: МАКС Пресс, 2013. 248 с.

6. Кеннеди П. Взлеты и падения великих держав: Экономические изменения и военные конфликты в формировании мировых центров власти с 1500 по 2000 г. / пер. с англ. Е. Калугина, М. Леоновича; предисл. В. Рыжкова. Екатеринбург: Гонзо, 2018. 848 с.

7. Коваленко В. Н. Экономическое сотрудничество со странами Африки в глобальной стратегии КНР // Китай, китайская цивилизация и мир. История, современность, перспективы: тез. Докл. XXII Междунар. науч. конф. (Москва, 12-13 октября 2016 г.) М.: ИДВ РАН, 2016. 184 с.

8. Лексютина Я. В. Китай и реформирование международной экономической системы // Сравнительная политика. 2018. № 3. С. 26-41.

9. Никитин А. И. Современный миропорядок: его кризис и перспективы. Полис. Политические исследования. 2018. № 6. С. 32-46. DOI: 10.17976/jpps/2018.06.03.

10. Пантин В. И., Лапкин В. В. Трансформации политических пространств в условиях перехода к полицентричному миропорядку. Полис. Политические исследования. 2018. № 6. C. 47-66. DOI: 10.17976/jpps/2018.06.04

11. Портяков В. Я. Муравей грызет кость. Избранные очерки о Китае: монография. М.: Изд-во ФОРУМ, 2018. 464 с.

12. Портяков В. Я. Шэньчжэньский камертон. Трансформация модели экономического роста в Китае и развитие Шэньчжэня: монография. М. : Изд-во ФОРУМ, 2017. 156 с.

13. Романовский Н. В. Памяти И. М. Валлерстайна // Социологические исследования. 2019. № 9. С. 168-168.

14. США - Китай: борьба двух стратегий и практик мирового лидерства / под ред. Л. С. Вартазаровой, И. Я. Кобринской. М.: ИМЭМО РАН, 2018. 65 с. DOI:10.20542/978-59535-0537-6

15. Тимофеев О. А., Ронжина В. С. Сопряжение программ «Сделано в Китае - 2025» и Industrie 4.0 как основа инновационного сотрудничества КНР и Германии // Китай в мировой и региональной политике. История и современность: ежегодное издание / сост., отв. ред. Е. И. Сафронова. М.: ИДВ РАН, 2017. Вып. ХХІІ. 400 с.

16. Труш М. С. Отношения КНР и США в экономической сфере: двусторонние связи и многосторонние экономические проекты // Сравнительная политика. 2017. № 3. С. 5271. DOI: $10.18611 / 2221-3279-2017-8-3-52-71$

17. Ц Цзяньжун Ч. Гонконг, Шанхай и Владивосток: в поисках дополнительных инструментов привлечения инвестиций на Дальний Восток России // Актуальные проблемы развития КНР в процессе ее регионализации и глобализации: материалы Х Междунар. науч.практ. конф. / науч. ред. Т. Н. Кучинская, В. С. Морозова. Чита: Изд-во ЗабГУ, 2018. 241 с.

18. China and Africa: Building peace and security cooperation on the continent / C. Alden, [et al.]. Palgrave Macmillan, Cham. Switzerland, 2018. 403 p.

19. Annual Report to Congress: Military and Security Developments Involving the People's Republic of China. 2018. P. I-III. URL: https://media.defense.gov/2018/Aug/16/2001955282/1/-1/1/2018-china-military-power-report.pdf (дата обращения: 10.08.2019).

20. Arduino A. China's Private Army: Protecting the New Silk Road [Электронный pecypc]. 2018. URL: https://doi.org/10.1007/978-981-10-7215-4 (дата обращения: 12.09.2019). 
21. Arrighi G. Adam Smith in Beijing: Lineages of the Twenty-first Century. N. Y., Verso, 2007. $418 \mathrm{p}$.

22. Babones S. American «tianxia»: Chinese money, American power, and the end of history. $2017.88 \mathrm{p}$.

23. Cheng Yu., Song L., Huang L. The Belt \& Road: Initiative in the Global Arena Chinese and European Perspectives, 2018 [Электронный ресурc]. URL: https://doi.org/10.1007/978981-10-5921-6_1 (дата обращения: 12.09.2019).

24. China in the international economic order: new directions and changing paradigms / edited by Lisa Toohey, Colin B. Picker, Jonathan Greenacre. Cambridge: Cambridge University Press, 2015. 344 p.

25. China's new sources of economic growth: human capital, innovation and technological change. Vol. 2 / Ligang Song, Ross Garnaut, Cai Fang, Lauren Johnston, ed. URL: http://www.iberchina.org/files/2017/economic_growth_china_anu.pdf (дата обращения: 10.10.2019). DOI: 10.1007 / 978-3-662-49448-6

26. Fang C., Yu D. China's New Urbanization Developmental Paths / Blueprints and Patterns // Springer Geography. 2016. P. 1-48. DOI: 10.1007 / 978-3-662-49448-6_1

27. Frank A. G. ReOrient: Global Economy in the Asian Age. Berkeley, Los Angeles, London, University of California Press, 2011. P. 1-48.

28. Fulong Wu (ed.) Globalization and the Chinese City. L., 2006. P. 272.

29. Gabuev Alexander. Crouching Bear, Hidden Dragon: «One Belt One Road» and Chinese-Russian Jostling for Power in Central Asia // Journal of Contemporary East Asia Studies. 2016. 5:2, P. 61-78. DOI:10.1080/24761028.2016.1186909

30. Governance, Social Control and Legal Reform in China Community Sanctions and Measures, 2018. P. 5 [Электронный ресурс]. URL: https://doi.org/10.1007/978-3-319-71864-4 (дата обращения: 12.09.2019).

31. Grell-Brisk M. China and global economic stratification in an interdependent world. Palgrave Communications 3. Nature Publishing Group, 2017. URL: https://www.nature.com/articles/ palcomms201787 (дата обращения: 10.10.2019).

32. Gulick J. The Long Twentieth Century and Barriers to China's Hegemonic Accession // Journal of World-Systems Research. Vol. XVII, № 1. 2011. P. 4-38.

33. Herrington M. L. Why the Rise of China Will Not Lead to Global Hegemony, Jul. 15, 2011 [Электронный ресурc]. URL: https://www.e-ir.info/2011/07/15/why-the-precarious-riseof-china-will-not-lead-to-global-hegemony (дата обращения: 12.09.2019).

34. Hong Zhou (ed.) China-EU relations: reassessing the China-EU comprehensive strategic partnership. Singapore, 2017. P. 219-226. DOI: 10.1007/978-981-10-1145-0

35. Ho-Fung H. Hegemonic Crisis, Comparative World-Systems, and the Future of Pax Americana // Journal of World-Systems Research. Vol. 23, is. 2. DOI: 10.5195/JWSR.2017.723 jwsr.org

36. Human Rights Watch 2018 [Электронный ресурc]. URL: https://www.hrw.org/world report/2018/country-chapters/china-and-tibet (дата обращения: 12.09.2019).

37. Kathleen C. Schwartzman Will China's Development lead to Mexico's Underdevelopment // Journal of World-Systems Research. 2014. Vol. 21, № 1. (Winter/Spring Issue). P. 106123.

38. Wang and Jiaping Wu // T. G. McGee [et al.] 2007, China's Urban Space Development under market socialism. L.; N. Y.: Routledge, 2007. 200 p.

39. Michael J. Sandel and Paul J. D'Ambrosio (ed.) Encountering China and Chinese Philosophy. Cambridge, 2018. P. 320.

40. Min Zhou (ed.) Contemporary Chinese Diasporas. Singapore, 2017. P. 16. DOI: $10.1007 / 978-981-10-5595-9$

41. Moisés N. The End of Power: From Boardrooms to Battlefields and Churches to States, Why Being in Charge Isn't What It Used to Be // Basic Books. 2013. 306 p. 
И. В. Купряшкин. Накануне гегемона? Мир-системный подход к перспективе глобального лидерства KHP

42. Prathibha M. S. ed. East Asia Strategic Review: China's Rising Strategic Ambitions in Asia. New Delhi, 2018. P. 278 p.

43. Qunhui H. China's Industrialization Process. 2018 [Электронный ресурc]. URL: https://doi.org/10.1007/978-981-10-3665-1 (дата обращения: 25.05.2019).

44. Ramesh S. China's Lessons for India: The Political Economy of Change, 2017. P. 252262. DOI: $10.1007 / 978-3-319-58115-6$

45. Rumi A. «One Belt, One Road»: China's New Global Strategy // Journal of Contemporary East Asia Studies. 2016. 5:2. P. 3-22. DOI: 10.1080/24761028.2016.11869094

46. Sahan S. K., Sefika K. Territorial Contradictions of the Rise of China: Geopolitics, Nationalism and Hegemony in Comparative-Historical Perspective // Journal of world-systems research. 2017. Vol. 23, Is. 1. P. 5-35. DOI: 10.5195/JWSR.2017.591

47. Shepard W. Ghost Cities of China. The story of cities without people in the world's most populated country. L., 2015. 192 p.

48. Sui Y. China in Symbolic Communication: Routledge, 2017. 179 p.

49. The Soft Power 30 Report [Электронный pecypc]. URL: https://softpower30.com/wpcontent/uploads/2018/07/The-Soft-Power-30-Report-2018.pdf (дата обращения: 25.05.2019).

50. Tianxiang H. Copyright and Fan Productivity in China: A Cross-jurisdictional Perspective. Singapore, 2017. P. 265. DOI: 10.1007/978-981-10-6508-8

51. Tilt B. Dams and development in China: the moral economy of water and power: N. Y., 2015. 280 p.

52. Wang C. Changing international system structures and the Belt and Road initiative / M. Mayer (ed.), Rethinking the Silk Road. Singapore, 2018. P. 287. DOI: 10.1007/978-981-10$5915-5$

53. Wallerstein I. China and the United States: Partners // Commentary. 2017. № 441. [Электронный ресурс]. URL: https://www.iwallerstein.com/china-and-the-united-states-partners. (дата обращения: 10.10.2019).

54. Wallerstein I. The End of the World As We Know It: Social Science for the TwentyFirst Century, Minneapolis. MN: University of Minnesota Press, 1999. 278 p.

55. Wallerstein I. This is the end, this is the beginning // Commentary. July 1, 2019. No. 500 [Электронный ресурc]. URL: https://www.iwallerstein.com/this-is-the-end-this-is-the-beginning (дата обращения: 10.10.2019).

56. Zhifan L. Intrastate Dynamics in the Context of Hegemonic Decline: A Case Study of China's Arms Transfer Regime // Journal of world-systems research. 2017. Vol. 23, Is. 1. P. 36-61. DOI: 10.5195/JWSR. 2017. 600.

\title{
ON THE EVE OF HEGEMON? \\ A WORLD-SYSTEM APPROACH TO THE PERSPECTIVE OF THE PRC GLOBAL LEADERSHIP
}

\author{
Ilya V. Kupryashkin \\ Cand. Sci. (Philos.), A/Prof., \\ Far Eastern Federal University \\ 8 Sukhanovoy St., Vladivostok 690091, Russia \\ E-mail: kupryashkin.iv@dvfu.ru
}

The article is written in memory of the founder of a world-system analysis, classic of historical sociology, president of the international sociological association (1994-1998) Immanuel Wallerstein. We have joined the discussion regarding the prospects for global leadership of the People's Republic of China in the modern world economy, and asked the question: "Are we witnessing the emergence of China's hegemony while the USA is losing their leadership position?". The article analyzes the achievements of China and 
its influence on the global economy in a variety of aspects, presents a brief look at the internal contradictions and problems of the country's development. We have made a review of some ideas regarding the perspective of China's hegemony with emphasis on the world-system approach developed by I. Wallerstein. In conclusion, we haven't given an unambiguous answer to his question, but offered new subjects for analytics.

Keywords: society; China; the USA; hegemony; world-system analysis; globalization; Immanuel Wallerstein. 